\title{
THE COVID-19 PANDEMIC: AN ANALYTICAL STUDY ON OPPORTUNITIES FOR CIRCULAR ECONOMY PRACTICES IN INDIA'S HEALTHCARE SECTOR
}

\author{
Sonal Narang ', Dimpal Vij2*, \\ 1. Research Scholar, MMH College, Ghaziabad, U.P., India \\ 2. Department of Economics, MMH College, Ghaziabad, U.P., India
}

Correspondence:dimpal.vij@rediffmail.com

\begin{abstract}
COVID-19 pandemic has long-lasting impact in social, personal, and economic area globally. When we think of the economic recovery of India in the future, we face the challenge of moving forward more sustainably. An international NGO ARUP had published a worldwide report named 'Health.Care. Without.Harm'; mentioning that only healthcare sector itself is accountable for about 4.4 percent of universal net emissions. The present study, therefore, highlights the vulnerabilities in the linear economy and how the pandemic crisis challenges the linear economy and provide opportunity to uptake circular practices and sustainable development within India's healthcare economy. The paper outlines the recommendations on the circular economy by suggesting policy and market-driven solutions for the healthcare sector's sustainability.
\end{abstract}

\section{KEYWORDS}

Pandemic, COVID-19, Circular Economy, Healthcare sector, India

\section{INTRODUCTION}

COVID-19 is seen as a'crisis like no other', the entire world economyis turning down. This is the erain which humanity's impact on nature has begun to impact on us in disastrous and unpredictable ways. This pandemic has made us realize that if we wish to avoid disasters we should invest in research, in basic public health, in production of vaccines and essential equipment for hospitals. And mostimportant is to optimally utilize our natural resources as there cannot be imbalance with the specific demand and supply responsible for consumption of many available and important natural resources. Realizing the challenge of scarcity of resources in future, the world is forced to think about the new ways; to produce, distribute, purchase and consume giving us a unique linear economy model; a new way representing the current circular economy model. This concept offers a way to rethink production and consumption on a systematic level. 
For ages our economy has been 'linear' in which raw materials are castoff to produce any product, make use of it and its waste like packaging is thrown away. Waste does not often recycle adequately and hence ends up in air, soil, and water environment of the planet which results in different kinds of pollution like air, water and soil resulting in the depletion of the natural resources, which in turn affects the human health. Hence, the foremost motive of a circular economy is to deliver the society in such a way that it least compromises the needs of future generation. Circular economy is evolving speedily, specially at present when humanity is facing various issues including environmental devastation, pandemic, and climate change.

A researcher [1] comprehensive research with an NGO named HCWH (Health Care Without Harm) based on worldwide comprehensive reports on healthcare found out that total emissions in healthcare sector are mostly equal to the gases produced in greenhouse by 514 coal fired based Power Plants annually. [1] Not only doctors, nurses and health facilities are responders to the impacts of climate change, but hospitals and healthcare systems make a major contribution to the climate crisis. Every nation's health sector release greenhouse gas either directly or indirectly.

During past three decades, the healthcare industry has become increasingly reliant on single-use disposable medical devices that include all equipment used in provision of medical care that does not primarily function through biological or chemical means. [2] This linear model of production and consumption effects human health the most as it contributes to global ecological destruction by depleting natural resources and generating excessive solid waste and harmful environmental emissions. Hence, it is essential to transform the healthcare sector to circular economy. [3]

\section{LITERATURE REVIEW}

MacNeill [2] has clearly explained the importance of a circular economy specifically in the healthcare sector of the US economy which still relies on linear supply chain manufacturing. Goyal [4] discussed the imbalance in demand and supply balance in consumption of natural resources due to the linear economic model as it affects the sustainability of the countries and therefore suggested the need for a circular economy model. Parashar [5] stated that plastic can be a protector if complemented by the circular economy strategies in terms of recycling and recovery. Fiksel [3] argued that achieving resilience will require both enlightened government policies and successful initiatives by social and environmental innovators that demonstrate the capacity for adapting to these challenges. Ibn-Mohammed et als. [6] paper describes some sector-specific recommendations on solutions related to circular economy for its globally economic development in the post-COVID-19 era. Wuyts [7] discussed interaction between principles of CE (Circular Economy) along with its issues linked to the pandemic situation in its healthcare sector.

\section{OBJECTIVES OF THE STUDY}

1. To find vulnerabilities associated with the current linear economy structure of the healthcare sector in India.

2. To examine constraints to achieve circular healthcare economy in India.

3. To suggest policy and market-driven solutions to transform the health care sector into a circular economy in the country.

\section{RESEARCH METHODOLOGY}

This study is based upon secondary data. It uses analytical and descriptive technique to find difficulties in linear economy structure and the merits of circular economy in healthcare sector specially post COVID-19 through different research papers, articles, different reports published by an NGO (Health Care Without Harm), Circularity Gap Report 2020 and 2021, WHO, (World Health Organization), CPCB, (Central Pollution Control Board), etc. Data from various sources have been gleaned, analyzed and conclusions drawn.

\section{Vulnerabilities associated with linear healthcare economy in India}

In a traditional healthcare economy, we take natural resources from the environment, make the devices, use them in hospitals and then throw them away. It is also known as 'take-make-dispose' approach. And there are various reasons for pursuing the linear economy model:

- The perception that if we throw used devices, we reduce infection risk.

- It is difficult to re-use as it requires the collection, transportation, cleaning, testing and sometimes sterilization before re-use. 
- Investment to re-use is more than the price of the device.

But the current economic pressures on healthcare have shown that the linear model is not sustainable as it simply costs too much and is bad for the environment. Several studies have compared about the equipment whether it's for single time use or reusable equipment and revealed that single-use disposables typically result in higher petrochemical use and global greenhouse gas emissions on a life-cycle basis. [8] In fact, cost-effectiveness studies further reveal that although costs of single use equipment acquisition are mostly lesser. But in case of multiple usage equipment, cost is evenly distributing for multiple usage depicting its feature of the lifetime lesser cost because of reusables substantially; presenting it as a lower costly equipment than about the equipment of single-use disposables. [9]

According to Central Pollution Control Board, daily generation of bio medical waste in India has increased by twenty five percent (25\%) in 2020 because of COVID-19. Prior this pandemic, the generation of regular bio-medical waste was 610 tons per day. But during this pandemic, the generation of waste increased to 765.5 tons per day (till December 2020) (see Figure 1)

FIGURE 1. BIO-MEDICAL WASTE GENERATION IN INDIA BEFORE COVID-19 AND DURING COVID-19

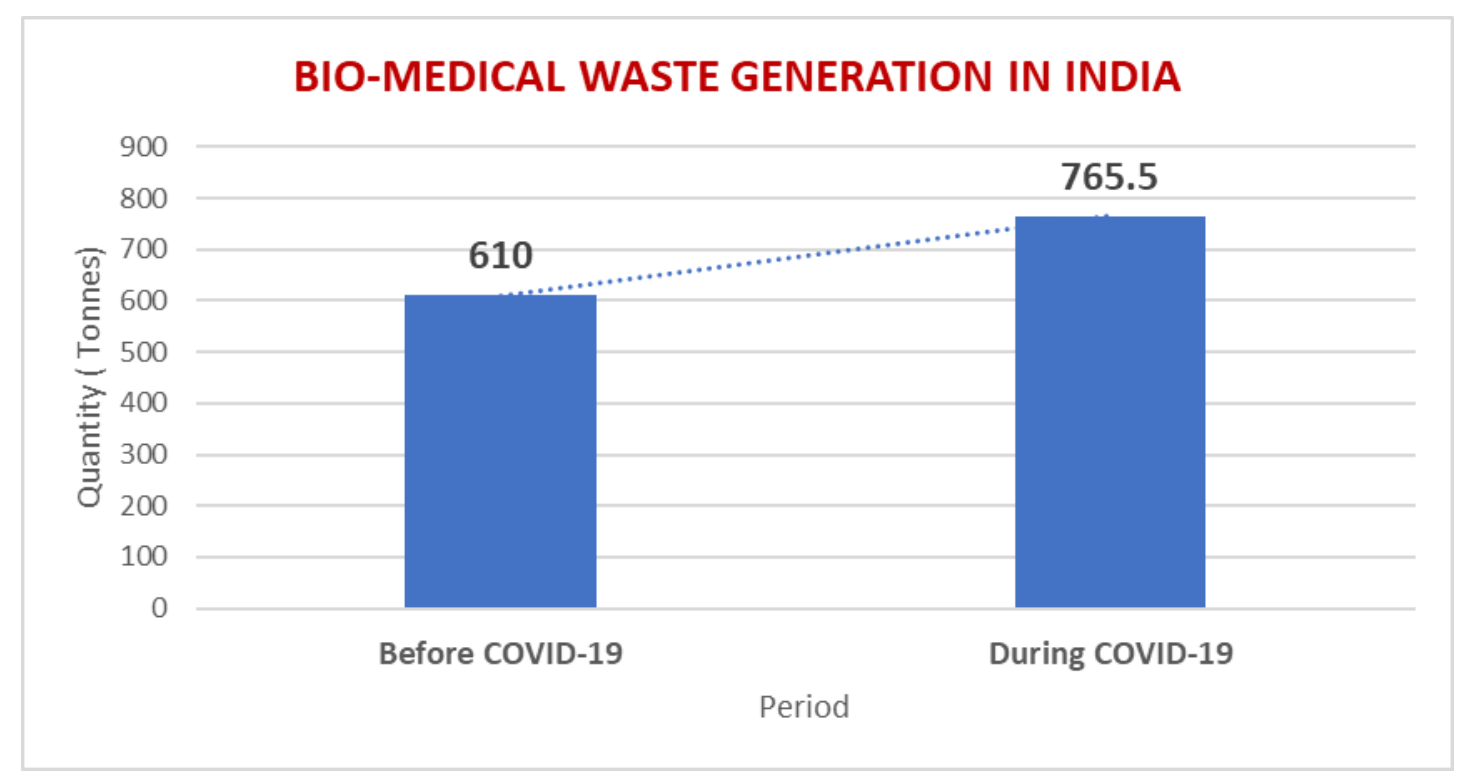

Source: Data compiled from СPCB Reports [10]

FIGURE 2. AVERAGE QUANTITY OF COVID-19 RELATED BIOMEDICAL WASTE GENERATION

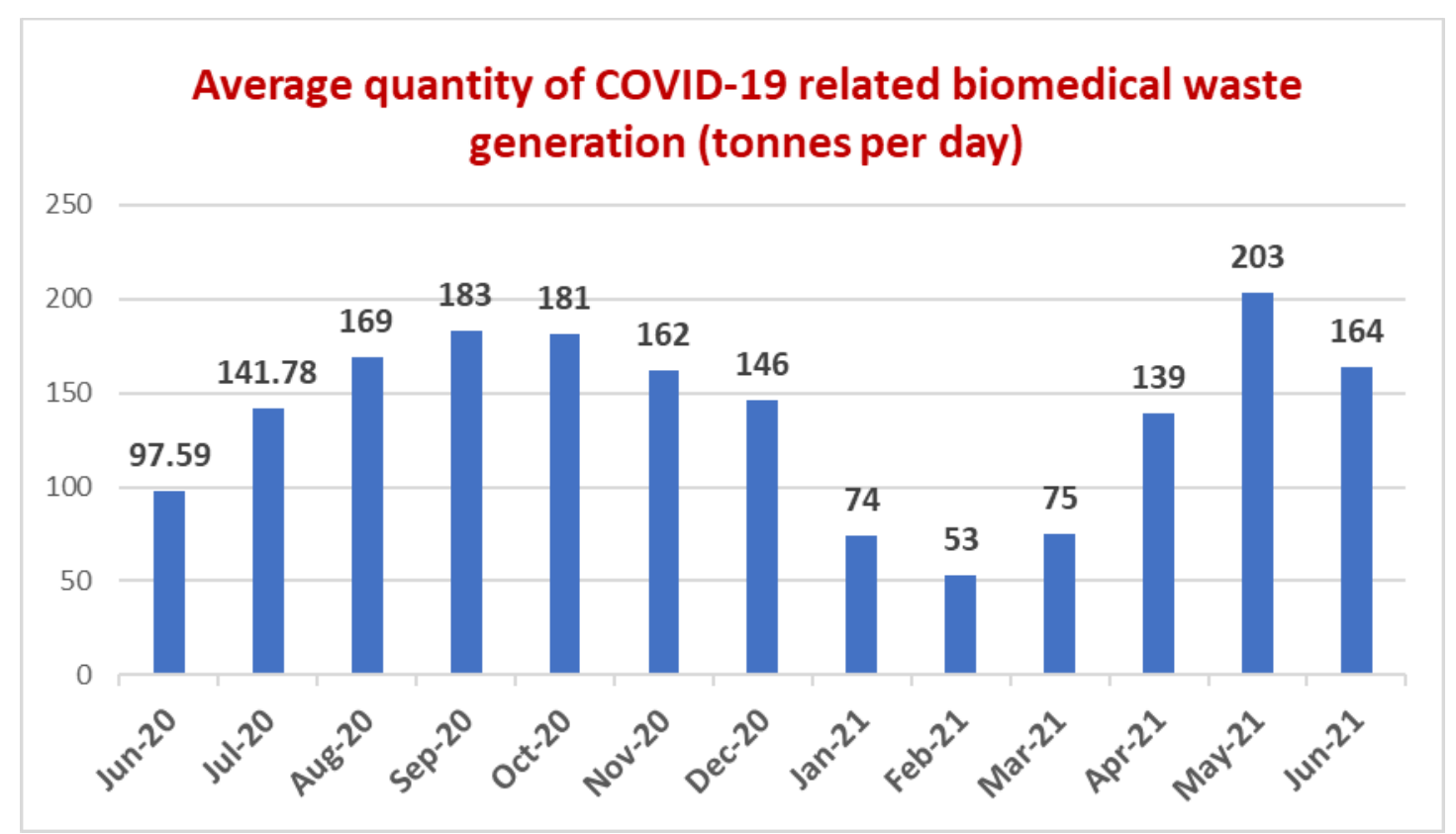

Source: Data compiled from different CPCB reports (Central Pollution Control Board) 
As cumulative waste calculated from average waste per day shown in figure 2 and from data by the MoEF\&CC (Ministry of Environment, Forest and Climate Change) represents the data about the generation of 56,898 tonnes of COVID-19 bio medical waste between June 2020 and June 2021 nationwide.

In May 2021, Central Pollution Control Board reported maximum COVID-19 waste generation; biomedical waste generated was 800 tonnes per day. Though as per the report submitted to the National Green Tribunal on January 14, 2021, CPCB stated that the treatment capacity of
CBWTFs (Captive bio-medical waste treatment and disposal facilities) is 826 tonnes of biomedical waste per day which was later corrected and decreased to 754 tonnes a day and proved that the treatment facilities are efficient to handle a rise in COVID-19 waste that has witnessed couple of times from June 2020 to June 2021 as shown in the following table. Closer analysis of state wise treatment capacity of biomedical waste in India found that out of 35 UT/States 22 were having less capacity in comparison to the biomedical waste they were generating (see Table 1)

TABLE 1: STATES/UTS GENERATING MORE OR LESS WASTE THAN TREATMENT CAPACITY

\begin{tabular}{|c|c|c|c|}
\hline $\begin{array}{l}\text { States and Union } \\
\text { Territories }\end{array}$ & $\begin{array}{l}\text { Total biomedical } \\
\text { waste generated } \\
\text { (tonnes per day) }\end{array}$ & $\begin{array}{l}\text { Percentage share of } \\
\text { COVID-19 BMW } \\
\text { in the total }\end{array}$ & $\begin{array}{l}\text { Total treatment } \\
\text { capacity } \\
\text { (tonnes per day) }\end{array}$ \\
\hline Andaman \& Nicobar & 0.7 & $2 \%$ & 0.2 \\
\hline Andhra Pradesh & 25 & $40 \%$ & 25.7 \\
\hline Arunachal Pradesh & 0.5 & $22 \%$ & 1 \\
\hline Assam & 9.3 & $6 \%$ & 8.6 \\
\hline Bihar & 35.9 & $3 \%$ & 35.6 \\
\hline Chandigarh & 5.8 & $33 \%$ & 5.6 \\
\hline Chhattisgarh & 6.5 & $42 \%$ & 16.4 \\
\hline Daman \& Diu & 0.4 & $18 \%$ & 0.3 \\
\hline Delhi & 46.7 & $39 \%$ & 37.2 \\
\hline Goa & 1.9 & $23 \%$ & 2 \\
\hline Gujarat & 58.4 & $38 \%$ & 50.5 \\
\hline Haryana & 27.9 & $47 \%$ & 21 \\
\hline Himachal Pradesh & 5.7 & $40 \%$ & 4.2 \\
\hline Jammu \& Kashmir & 8.4 & $30 \%$ & 13.9 \\
\hline Jharkhand & 7.8 & $7 \%$ & 4.9 \\
\hline Karnataka & 94.5 & $18 \%$ & 72.6 \\
\hline Kerala & 66.6 & $36 \%$ & 89.5 \\
\hline Lakshadweep* & 0.1 & $9 \%$ & 72 \\
\hline Madhya Pradesh & 25.2 & $29 \%$ & 23.8 \\
\hline Maharashtra & 81.3 & $23 \%$ & 82.7 \\
\hline Manipur & 1.1 & $12 \%$ & 1.4 \\
\hline Meghalaya & 1.5 & $17 \%$ & 1.7 \\
\hline
\end{tabular}




\begin{tabular}{|llll|}
\hline Mizoram & 1 & $3 \%$ & 0.9 \\
\hline Nagaland & 0.7 & $11 \%$ & 0.2 \\
\hline Odisha & 24.6 & $27 \%$ & 18.7 \\
\hline Puducherry & 7.7 & $23 \%$ & 4.9 \\
\hline Punjab & 20.1 & $20 \%$ & 18.8 \\
\hline Rajasthan & 25.7 & $19 \%$ & 25.7 \\
\hline Sikkim & 0.5 & $3 \%$ & 0.5 \\
\hline Tamil Nadu & 71.8 & $19 \%$ & 55.3 \\
\hline Telangana & 25.4 & $20 \%$ & 18.4 \\
\hline Tripura & 1.42 & $1 \%$ & 1.4 \\
\hline Uttarakhand & 5.8 & $34 \%$ & 6.6 \\
\hline Uttar Pradesh & 68.4 & $23 \%$ & 61.4 \\
\hline West Bengal & 47.3 & $12 \%$ & 43.1 \\
\hline
\end{tabular}

Source: Data from Central Pollution Control Board [11]

*The data shows that Lakshadweep has a treatment capacity of 72 tons per day, but this is highly unlikely as the UT has no treatment plants.

Table prepared on the basis of biomedical waste generated in December 2020 and COVID-19 waste generation in May 2021 . Ladakh data is unavailable

Moreover, there is problem of missed biomedical waste means waste that is not being reported on BWM App as most of the time we find that general public including waste workers throw this waste (surgical masks, gloves, PPE kits, Face shields etc.) without segregating them and they are mixed with general solid waste and contaminating whole environment. The improper management of contaminated PPEs and healthcare waste might have increased the spread of viral disease in the environment as the use of surgical face masks, PPEs, medical gloves and aprons have been recommended for essential healthcare service staff and face masks use has been mandated for citizens. During a pandemic when demand goes up for certain types of devices, supplies cannot be found. And then the vulnerabilities were visible in the linear supply model as the linear economy is convenient under normal conditions, but it is highly responsible for the climatic crises. Thus, it is necessary to consider separation, storage and collection for recycling and disposing of medical waste and face masks to reduce plastic waste and adopt alternative technology in the form of waste with a view to facilitating energy recovery like usage of biodegradable products.

\section{Opportunities for circular healthcare economy in India}

2021 is the year when a circular healthcare economy has become a vital conversation in India. The pandemic has led to a focus on the need to re-use some medical devices and stresses over the need for hospitals to critically review their supply chain. As coronavirus waste has become a new form of pollution as single-use personal protective equipment (PPE), masks and gloves and other coronavirus waste like hand sanitizer bottles are used and thrown away every single day. There is a clear pathway to supply chain solutions that simultaneously reduce costs and environmental impact. This economy that is restorative and regenerative by design is a circular economy. It builds and rebuilds overall system health, and is based on three principles:

- Optimum utilization of waste by reuse of used bio medical products.

- Revitalizing natural resources.

- Eradicate pollution. 
This transformation from the linear economy to a circular economy will take time and there are several challenges for the healthcare sector. These include:

- $\quad$ Single-use device reprocessing challenges the singleuse mindset in healthcare.

- Cost-benefit analysis should be performed to determine that re-use doesn't imply added costs.

- Safety measures should be taken to clean and re-use the selected supplies because of safety risks for patients.

- Economical and feasible remanufacturing process.

- To create collection re-use infrastructure, which includes containers to place used supplies, buying back of supplies into the inventory management system.

- Appropriate training to staff to follow collection and reuse instructions.

Reprocessing is the traditional circular economy solution. It may be the only circular healthcare economy model that can be accepted easily. Because of this, hospitals can drive additional savings and promote a more sustainable Indian healthcare system.

Due to climate change, adopting a circular economy is critical for all companies across the spectrum, but a circular economy drives greater jobs creation which is due to higher spending from lower prices and labor-intensive recycling activities. Moreover, through greater innovation and an emerging service-based economy, new roles are created in SMEs. In India, we already have a sharing and repair-ability culture, we just need to embrace it to meet our climate change objectives.

\section{RECOMMENDATIONS AND CONCLUSION}

During pandemic, we realized that the planet's health is our health. Thus, it is imperative to re-think the undertaken measures during COVID-19 to minimize the negative consequences in the future. The repair economy may be more practical than long supply chains delivering cheaper goods as it provides a way to maximize equipment's productivity, minimize waste and achieve sustainable standards. The government should introduce 'Right to Repair' for a Circular healthcare economy for environment sustainability by allowing medical equipment to flow through technological cycles of repair, reprocessing, and reuse. For this, products should be designed to be able to be repaired multiple times before they have to be recycled and it requires innovation and research. Thus, a key feature of the circular economyis design for durability.

As shown in Table 1, an analysis of CPCB's reports of January and May 2021 suggests that treatment capacity of 22 out of 35 states and Union Territories to generate more bio-medical waste is inefficient. So, government should increase the treatment facility of inefficient states and UTs like Maharashtra, Tamil Nadu, Delhi, etc., and if it is not possible then circular economy plays an important role to solve the problem by creating the reusable products. Creation of reusable products also help in the sustainability of natural resources. Establishment of more recyclable units which will create more job opportunities as well.

Segregation has been a major concern in our country and burning of plastics also releases harmful gases which results in environmental pollution, that's why more biodegradable waste plastics should be used to make PPE kits, gloves, shoe covers, etc.

Hence, the need is to make healthcare sector green which requires:

- Change in perception of human beings, especially doctors and patients.

- Efficient planning and policymaking by the civil administration.

- Use of technology.

- Safeguard citizens' health and safety.

So, India should also adopt the strategy of reprocessing and repairs for eliminating hospital waste and improving environmental sustainability because we desperately need transformative and corrective solutions as change is a must. Healthcare workers, manufacturers and patients should work with the government to guarantee the right infrastructure, fiscal matters and long-term vision to empower change as there are various challenges like safety, security and adaptability that must be considered during the process of this circular economyrevolution.

\section{References}

1. J. Karliner, S. Slotterback, R. Boyd, B. Ashby and K. Steele, "Health Care's Climate Footprint: How the Health Sector Contributes to the Global Climate Crisis and Opportunities for Action: Healthcare Without Harm," ARUP, 2019. 
2. A. MacNeill, H. Hopf, A. Khanuja, S. Alizamir, M. Bilec, M. Eckelman, L. Hernandez, F. McGain, K. Simonsen, C. Thiel and S. Young, "Transforming the Medical Device Industry: Road Map to a Circular Economy: Study examines a medical device industy transformation.," Health Affairs, vol. 39, no. 12, pp. 2088-2097, 2020.

3. J. Fiksel, P. Sanjay and K. Raman, "Steps toward a resilient circular economyin India," Clean Technologies and Environmental Policy, vol. 23, no. 1, pp. 203-218, 2021.

4. S. Goyal, M. Esposito and A. Kapoor, "Circular economy business models in developing economies: lessons from India on reduce, recycle, and reuse paradigms," Thunderbird International Business Revieew, vol. 60, no. 5, pp. 729-740, 2018.

5. N. Parashar and S. Hait, "Plastics in the timme of COVID-19 pandemic: Protector or polluter?" Science of the Total Environment, vol. 759, p. 144274, 2020.

6. T. Ibn-Mohammed, K. Mustapha, J. Godsell, Z. Adamu, K. Babatunde, D. Akintade, A. Acquaye, H. Fujii, M. Ndiaye, F. Yamoah and S. Koh, "A critical analysis of the impacts of COVID-19 on the global economy and ecosystems and opportunities for circular economy strategies.," Resources, Conservation and Recycling, vol. 164, p. 105169, 2021.

7. W. Wuyts, J. Marin, J. Brusselaers and K. Vrancken, "Circular economy as a COVID-19 cure?" Resources, Conservation, and Recycling, vol. 162, p. 105016, 2020.

8. J. Sherman, L. Raibley IV and M. Eckelman, "Life cycle assessment and costing methods for device procurement: comparing reusable and single-use disposable laryngoscopes.," Anesthesia \& Analgesia, vol. 127, no. 2, pp. 434-443, 2018.

9. S. Sanchez, M. Eckelman and J. Sherman, "Environmental and economic comparison of reusable and disposable blood pressure cuffs in multiple clinical settings," Resources, Conservation and Recycling, vol. 155, p. 104643, 2020.

10. A. Bhatia, "In Last Seven Months, India Generated Around 33,000 Tonnes COVID-19 Waste, Maharashtra Biggest Contributor: Report," 12 January 2021 . [Online]. Available: https://swachhindia.ndtv.com/in-lastseven-months-india-generated-around-33000-tonnescovid-19-waste-maharashtra-biggest-contributorreport-55181/amp/ [Accessed 23 November 2021].
11. S. Singh, "COVID-19 will place India's biomedical waste management under terrible strain," 30 June 2021. [Online]. Available:

https://www.downtoearth.org.in/news/waste/amp/co vid-19-will-place-india-s-biomedical-wastemanagement-under-terrible-strain-77714. [Accessed 23 November 2021]. 